\title{
Surgical Complications and Evolution of Grafts in Children with Renal Transplantation at Cayetano Heredia National Hospital
}

\author{
Roberto Sanchez ${ }^{1,2 *}$, Reyner Loza ${ }^{2,3}$, Cesar Loza ${ }^{2,4}$, Luis Zegarra ${ }^{1,2}$ \\ ${ }^{1}$ Surgery and Urology Unit, Department of Surgery, Cayetano Heredia Hospital, Lima, Peru \\ ${ }^{2}$ Renal Transplant Unit, Cayetano Heredia Hospital, Lima, Peru \\ ${ }^{3}$ Paediatric Nephrology Unit, Department of Pediatrics, Cayetano Heredia Hospital, Lima, Peru \\ ${ }^{4}$ Nephrology Service, Department of Medicine, Cayetano Heredia Hospital, Lima, Peru \\ Email: *robmedic1@hotmail.com
}

Received April 18, 2013; revised May 9, 2013; accepted June 10, 2013

Copyright (C) 2013 Roberto Sanchez et al. This is an open access article distributed under the Creative Commons Attribution License, which permits unrestricted use, distribution, and reproduction in any medium, provided the original work is properly cited.

\begin{abstract}
Objective: This study aims to determine surgical complications and graft outcome in children undergoing renal transplantation at Cayetano Heredia National Hospital $(\mathrm{CHNH})$. Materials and Methods: A case study series focused on the incidence of surgical complications and graft outcome in pediatric patients with end stage renal disease (ESRD) who underwent renal transplant (RT) between December 2007 and March 2011. Results: The study described 29 pediatric transplant patients whose average age was $13.69 \pm 3.38(6.2-17.9)$ years. The etiology of end stage renal disease (ESRD) was renal hypoplasia in 12 patients $(41.38 \%)$, primary glomerulopathy in 10 patients $(34.48 \%)$, obstructive uropathy in 4 patients $(13.79 \%)$, vasculitis in 2 patients $(6.9 \%)$ and hemolytic uremic syndrome (HUS) in $1(3.45 \%)$ patient. There were 11 surgical complications (34.48\%): 2 cases of arterial thrombosis, 3 cases of urinary fistula, 3 of lymphocele, 1 of venous thrombosis, urinoma and perineal collection. The follow-up time was $15.84 \pm 12.19$ months. Graft survival at 12, 24, and 40 months was $89.29 \%, 77.16 \%$ and $77.16 \%$, respectively. Conclusion: Surgical complications and graft survival in pediatric renal transplantation in our series did not differ from other published series.
\end{abstract}

Keywords: Children; Terminal Chronic Renal Disease; Renal Transplantation; Surgical Complications

\section{Introduction}

ESRD, defined as a permanent loss of the kidneys' ability to filter waste from the circulatory system, is a global public health problem of growing proportions [1]. Its prevalence in the pediatric population fluctuates between 5 to 10 children per million per year. Forty years ago, children with ESRD died. However, current renal replacement (RRT) therapies used in children have changed this bleak picture significantly, enabling almost all children to be treated by dialysis or renal transplantation (RT). RT has been shown to be the therapy of choice for this population, resulting in better long-term survival and quality of life [2]. The costs of transplanted organ maintenance are low compared to other methods of RRT. Dialysis provides only a fraction of normal renal clearance, relieves but does not remove uremic symptoms such as fatigue and anorexia, and does not resolve the

${ }^{*}$ Corresponding author. anomalies of growth and development. In contrast, RT can provide kidney function equivalent to 40 to 80 per cent of normal renal function [3-8]. Advances in anesthesia, surgical techniques, and the discovery of immunosuppressants have allowed a progressive reduction in the contraindications to this procedure, even though the biological behavior and potential complications in transplanted children differ to those in adults $[4,9,10]$. Globally, surgical complications affect survival and renal graft loss, so early diagnosis and prompt treatment are important. Surgical complications in renal transplantation are defined as complications that occur during surgery and the postoperative follow-up. They are classified as vascular, urological, and collections and have an incidence ranging from $1 \%$ to $38 \%$ [9-15]. RT surgery has been performed in Peru since the 1960s. Augusto Hernandez Mendoza, a urologist, performed the first RT, and followed by Raul Romero Torres, who established the transplant unit at the Naval Medical Center 
in August 1969. In the same year, the first kidney transplant was carried out under the Peruvian social insurance system [16]. In July 2007, a renal transplant pilot program at Cayetano Heredia National Hospital was funded. In the same year, the $\mathrm{CHNH}$ was accredited by the National Organization of Organ and Tissue Transplants (ONDT) as a transplant-donation center, performing its first kidney transplant on December 14, 2007, on a pediatric patient [17]. To date, 51 patients, both adults and children, have received transplants. The aim of the present study was to describe the incidence of surgical complications and evolution of the renal graft in children who received transplants

\section{Material and Method}

Reviewed twenty-nine medical records of pediatric patients (under 18 years) who received transplants (28 from living donors and 1 from a nonliving donor) between December 2007 and March 2011. Any event that occurred in the intra- and/or postoperative period, classified as vascular, urological, and/or collection, was defined as a surgical complication. In all transplants, lateral anastomosis was performed of the artery and renal vein from the donor to the external iliac vein and artery from the receptor, respectively. For ureteral reimplantation the Politano-Leadbetter technique was performed in 2 patients, and Lich-Gregoir in 27 patients, with posterior ureteral catheterization in a systematic way. The Jackson-Pratt drain was left in the first 22 patients and then laminated to the retro peritoneum. Some patients had a urinary Foley catheter for 5 days. The immunosuppression process used was timoglobulina, daclizumab, and basiliximab induction therapy. The maintenance therapy was tacrolimus (Tac), mycophenolate mofetil (MMF), and prednisone $(\mathrm{Pd})$. The surgical complications found were vascular thrombosis, primary vascular anastomosis failure, lymphocele, urinoma, urinary fistula, perirenal collection, intestinal blockage by adhesions, and secondary adherence to a previous umbilical hernia surgery. Renal graft function was evaluated by measuring creatinine serum and clearance of creatinine. A Doppler ultrasound was performed on the graft 24 hours after transplantation and during follow-up. For the analysis of the graft survival, loss of the graft was considered as a failure. According to Kaplan-Meier survival curves were performed. Data processing and statistical analysis were carried out using Stata version 11.

\section{Results}

The study population comprised 29 patients, 14 girls and 15 boys. The average age was $13.69 \pm 3,38$ (6. 2 - 17. 9) years. Sixteen of the children came from Lima (55.17\%) and 13 from other cities in Peru (44.83\%)
The etiology of the ESRD in the patients was renal hypoplasia in $12(41.38 \%)$, primary glomerulopathy in $10(34.48 \%)$, obstructive uropathy in $4(13.8 \%)$, vasculitis in $2(6.9 \%)$, and hemolytic uremic syndrome (HUS) in $1(3.45 \%)$.

At the time of the RT, 19 patients $(65.52 \%)$ were receiving peritoneal dialysis, 6 patients were receiving hemodialysis $(10.69 \%)$, and 4 patients (13.79\%) both therapies. The average time on dialysis was $3.26 \pm 2.20$ $(0.65-7.7)$ years. The related living donors were mothers in $23(79.31 \%)$ patients, fathers in 3 patients $(10.34 \%)$, and grandfather in one $(3.45 \%)$ patient. There was one unrelated living donor (adoptive mother) and a cadaver donor (Table 1).

In tests of histocompatibility (HLA), identity between the recipient and donor was as follows: $6 / 6$ in 1 case $(3.45 \%), 5 / 6$ in 4 cases $(13.79 \%), 4 / 6$ in 11 cases (37.94\%), 3/6 cases in $10(34.48 \%)$ cases, $1 / 6$ in 2 cases $(6.90 \%)$, and $0 / 6$ in 1 case $(3.45 \%)$.

The duration of warm ischemia was $1.85 \pm 0.94(0.83-$ 5) minutes, and cold ischemia $173.83 \pm 205.11$ (49 $1200)$ minutes, with a median of 140 minutes. The duration of venous anastomosis was $31.86 \pm 10.79(18-60)$ minutes and for arterial anastomosis $25.66 \pm 10.6(14-$ 48) minutes. Nine donors had a double renal artery (31.03\%).

Average post-operative hospitalization was $21.52 \pm$ 21.06 ( 7 - 113) days and the average follow-up period $15.84 \pm 12.19(0-39.57)$ months. The average glomerular filtration rate at the end of the observation period was $76.43 \pm 28.86(23-130) \mathrm{ml} / \mathrm{min} / 1.73 \mathrm{~m}^{2}$. In the followup period, the variation of post-transplant weight to basal weight was $7.28 \pm 6.57(-2.4-25.9) \mathrm{kg}$ and the average size gain $6.65 \pm 5.09(0-20) \mathrm{cm}$ (Table 2$)$.

Of the 29 patients, $12(34.48 \%)$ had surgical complications from the procedure and one had intestinal obstruction due to bands and adhesion without repercussion on the renal function of the graft (the patient had a history of surgery for umbilical hernia). Four patients had vascular complications, with arterial thrombosis in 2 patients $(6.9 \%)$ and venous thrombosis in $1(3.45 \%)$. Both led to loss of the graft. A fourth patient had a double artery with failure in the anastomosis in one; a reanastomosis was performed using the same surgical procedure without complications.

There were 3 urological complications (10.34\%), all urinary fistula (in 2 patients they were surgically repaired and in one there was spontaneous closure with the use of a urinary catheter). There were 5 collections, with diagnosis by ultrasound in all cases. Lymphocele occurred in 3 patients (10.34\%) (one was resolved by laparoscopic surgery and 2 reabsorbed spontaneously). There was one case of urinoma and another of perirenal collection (Table 3 ). Of the major medical complications, we found 
Table 1. Dialysis modality and type of donor in pediatric transplants at the national cayetano heredia hospital.

\begin{tabular}{ccc}
\hline Dialysis Modality & $\mathbf{n}$ & $\mathbf{\%}$ \\
\hline Peritoneal dialysis & 19 & 65.52 \\
Hemodialysis & 6 & 20.69 \\
Both & 4 & 13.79 \\
TOTAL & $\mathbf{2 9}$ & $\mathbf{1 0 0}$ \\
\hline & Type of donor & \\
\hline Mother & 23 & 79.31 \\
Father & 3 & 10.34 \\
Grandfather & 1 & 3.45 \\
Non-related donor & 1 & 3.45 \\
Cadaver donor & 1 & 3.45 \\
TOTAL & $\mathbf{2 9}$ & $\mathbf{1 0 0}$ \\
\hline
\end{tabular}

Table 2. Perioperative and evolutionary characteristics of pediatric patients receiving transplants at the national cayetano heredia hospital.

\begin{tabular}{cc}
\hline Variable & X \pm D.E. \\
\hline Duration of warm ischemia (minutes) & $1.85 \pm 0.94$ \\
Duration of cold ischemia (minutes) & $173.83 \pm 205.11$ \\
Duration of arterial anastomosis (minutes) & $25.66 \pm 10.6$ \\
Duration of venous anastomosis (minutes) & $31.86 \pm 10.79$ \\
Glomerular filtration rate (ml/min/1.73 $\left.\mathrm{m}^{2}\right)\left(^{*}\right)$ & $76.43 \pm 28.86$ \\
Hospitalization time (days) & $21.52 \pm 21.06$ \\
Variation of weight $(\mathrm{kg})$ & $7.28 \pm 6.57$ \\
Variation of size (cm) & $6.65 \pm 5.09$ \\
Average follow-up (months) & $15.84 \pm 12.19$ \\
\hline
\end{tabular}

*Last control in the follow-up.

Table 3. Surgical complications in pediatric patients undergoing transplant at the National Cayetano Heredia Hospital.

\begin{tabular}{ccc}
\hline Vascular complications & $\mathbf{n}$ & $\mathbf{\%}$ \\
\hline Arterial thrombosis & $\mathbf{4}$ & $\mathbf{1 3 . 8 0}$ \\
Venous thrombosis & 2 & 6.90 \\
Primary anastomosis failure & 1 & 3.45 \\
Urological complications & 1 & 3.45 \\
Urinary fistula & $\mathbf{3}$ & $\mathbf{1 0 . 3 4}$ \\
Collections & 3 & 10.34 \\
Lymphocele & $\mathbf{5}$ & $\mathbf{1 7 . 2 4}$ \\
Urinoma & 3 & 10.34 \\
Perirenal collection & 1 & 3.45 \\
Other & 1 & 3.45 \\
Intestinal obstruction & $\mathbf{1}$ & $\mathbf{3 . 4 5}$ \\
\hline
\end{tabular}

that urinary tract infection occurred in 9 patients $(34.61 \%)$ and a sharp rejection in 7 (26.92\%).

The overall graft survival 12, 24, and 40 months after renal transplantation was $89.29 \%$ (IC95\%: 70.36 - 96.41), 77.16\% (IC95\%: 51.82 - 90.28), and 77.16\% (IC95\%: 51, 82 - 90.28) respectively (Figure 1). There were 5 graft losses (17.24\%) after discharge from hospital with a functioning kidney: 3 due to vascular complications and 2 to medical complications (one due to nephrotoxicity to tacrolimus and the other to lack of adherence to the treatment).

\section{Discussion}

In our series, the most common etiology of the TCRD was renal hypoplasia, followed by the primary glomerulopathies, similar to that reported by Palacios et al. in Chile [4]. In the area covered by the Latin American Pediatric Nephrology Association (ALANEPE), the leading causes are obstructive uropathy and chronic glomerulopathy. In contrast, in the North American Pediatric Registry Transplant Cooperative Study (NAPRTCS), renal hypoplasia and obstructive uropathy are reported as the most frequent [14]. In Argentina, the primary cause in children is hemolytic uremic syndrome [8]. Our incidence of surgical complications was $34.48 \%$, which is similar to figures in the literature, highlighting that we have considered minor surgical complications that are usually not reported by other series such as El Atat et al. $(30 \%)$ and Barba et al. in Spain $(38 \%)[11,12]$. The incidence of vascular thrombosis was $10.34 \%$, which is comparable with other series such as El Atat et al. (18.9\%), Palacios et al. in Chile (9.2\%), and Irtan et al. (13.9\%) in France. In our series, 2 cases of vascular thrombosis were diagnosed during surgery and 1 on the fifth day postsurgery by a Doppler ultrasound scan $[4,11,18]$. The urological complication in our series was urinary fistula.

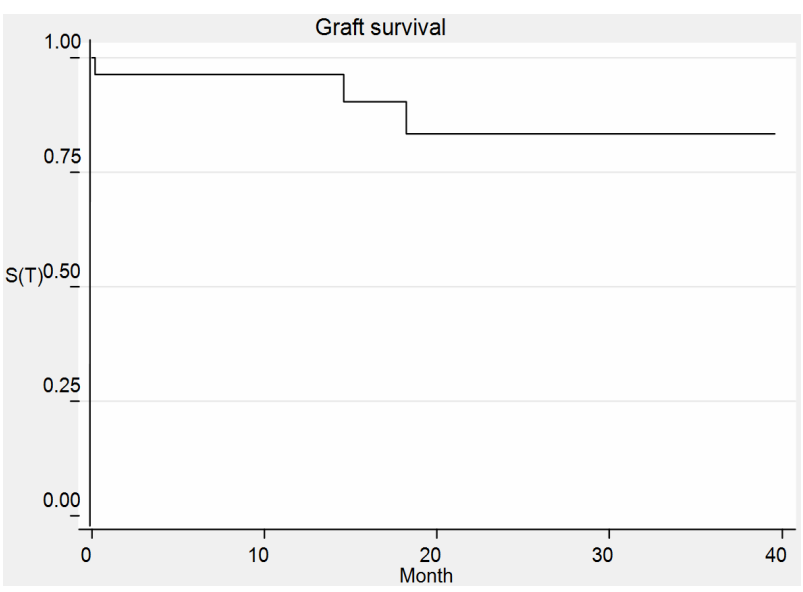

Figure 1. General survival of the graft in pediatric patients undergoing transplant at the National Cayetano Heredia Hospital. Period 2007-2011 (N = 29). 
This differs from other reports in the literature, which present problems between $3.1 \%$ and $30 \%$, with vesicoureteral reflux being the chief complication [18]. Among the most frequent collections, lymphocele (10.34\%) should be highlighted, which differs from that reported in adults (49\%) [6]. In all cases, diagnosis and follow-up were by ultrasound. It should be noted that the graft was lost in $17.24 \%$ of cases in our study, a similar situation to that reported by other series, for example Palacios (25\%). The overall survival rate of the graft was also similar to Palacios' data from Chile and Medeiros' data from Mexico $[4,6]$. In the NAPRTCS, the survival rate after 1 and 3 years was $96.5 \%$ and $91.5 \%$, respectively, and in ALANEPE 96\% and 93\% [14]. At study the mortality rate of our patients is zero, while Medeiros in Mexico reported a $4.3 \%$ mortality rate and the NAPRTCS a rate of $4.8 \%$ after 3 years [6].

\section{Conclusion}

The rates of complications in pediatric renal transplantation surgery in our series and the survival of renal grafts up to 40 months post-surgery do not differ from other international series.

\section{REFERENCES}

[1] T. Kalblea, M. Lucanb, G. Nicitac, R. Sellsd, F. J. Burgos, M. Wieselet, et al., "Eau Guidelines on Renal Transplantation," European Urology, Vol. 47, No. 2, 2005, pp. 156-166. doi:10.1016/j.eururo.2004.02.009

[2] S. P. McDonald and J. C. Craig, "Long-Term Survival of Children with End-Stage Renal Disease," The New England Journal of Medicine, Vol. 350, 2004, pp. 2654-2662. doi:10.1056/NEJMoa031643

[3] B. A. Warady, D. Herbert, E. K. Sullivan, et al., "The 1995 Annual Report of the North American Pediatric Renal Transplant Cooperative Study," Pediatric Nephrology, Vol. 11, No. 1, 1997, pp. 49-64. doi:10.1007/s004670050232

[4] J. M. Palacios, P. Rosati, E. Lagos, P. Hevia, S. Rodríguez, O. Jiménez, I. Turu and K. Cuevas, "Pediatric Renal Transplant: The Experience of a Center," Chilean Review in Surgery, Vol. 57, 2005, pp. 483-488

[5] A. Guardiola, F. Sánchez, L. Gimeno, et al., "Urological Complications in the Renal Transplant. Study in 250 Cases," Actas Urológicas Españolas, Vol. 25, No. 9, 2001, pp. 628-636. doi:10.1016/S0210-4806(01)72688-5

[6] M. Medeiros, B. Romero, S. Valverde, R. Delgadillo, G. Varela and R. Muñoz, "Pediatric Renal Transplant," Re- vista de Investigacion Clinica, Vol. 57, No. 2, 2005, pp. 230-236.

[7] A. E. Da Silveira, M. de Almeida, W. Cosenza, A. C. Amarante, R. de Menezes and E. Schulz, "Renal Transplant in Children: Analytical Study in 25 Cases," Revista Cirugia Infantil, Vol. 6, No. 4, 1996, pp. 172-176.

[8] V. Zúñiga and L. Álvarez, "Pediatric Renal Transplantation in the South Central Specialty Services Hospital (HC SAE) from PEMEX (México)," Mexican Nephrology, Vol. 22, No. 2, 2001, pp. 75-82.

[9] F. Cano and P. Rosati, "Pediatric Renal Transplant. A Decade of Multicentric Experience," Revista Chilena de Pediatria, Vol. 72, No. 6, 2001, pp. 504-515.

[10] O. Salvatierra, "Pediatric Renal Transplantation," Transplantation Proceedings, Vol. 31, No. 4, 1999, pp. 1787 1788. doi:10.1016/S0041-1345(99)00168-2

[11] R. El Atat, A. Derouiche, S. Guellouz, T. Gargah, R. Lakhoua and M. Chebil, "Surgical Complications in Pediatric and Adolescent Renal Transplantation," Saudi Journal of Kidney Diseases and Transplantation, Vol. 21, 2010, p. 251.

[12] J. Barba, A. Rincón, E. Tolosa, L. Romero, D. Rosell, J. E. Robles, et al., "Surgical Complications in Renal Transplantations and Its Influence in the Survival of the Graft," Actas Urológicas Españolas, Vol. 34, No. 3, 2010, pp. 266-273. doi:10.1016/S2173-5786(10)70059-7

[13] S. P. Lapointe, M. Charbit, D. Jan, S. Lortat-Jacob, J. L. Michel, D. Beurton, et al., "Urological Complications after Renal Transplantation Using Ureter Ureteral Anastomosis in Children," Journal of Urology, Vol. 166, No. 3, 2001, pp. 1046-1048. doi:10.1016/S0022-5347(05)65916-2

[14] Latin American Pediatric Nephrology Association, et al., "Latin American Registry of Pediatric Renal Transplantation 2004-2008," Pediatric Transplantation, Vol. 14, No. 6, 2010, pp. 701-708. doi:10.1111/j.1399-3046.2010.01331.x

[15] P. Fentes, B. Parra, T. Caamaño, et al., "Post Renal Transplant Surgical Complications. Study in 185 Cases," Actas Urológicas Españolas, Vol. 29, No. 6, 2005, pp. 578-586. doi:10.1016/S0210-4806(05)73300-3

[16] E. Barboza, "Advances in Surgery in the Last 30 Years," Revista Diagnostico, Vol. 47, No. 3, 2008, pp. 13-16.

[17] R.M. No 568-2007/MINSA, "The Pilot Program is Created Renal Transplants from the Ministry of Health," El Peruano, 15 July 2007, 349116.

[18] S. Irtan, A. Maisin, V. Baudouin, Y. Nivoche, R. Azoulay, E. Jacqz-Aigrain, A. El Ghoneimi and Y. Aigrain, "Renal Transplantation in Children: Critical Analysis of Age Related Surgical Complications," Pediatric Transplantation, Vol. 14, 2010, pp. 512-519. 